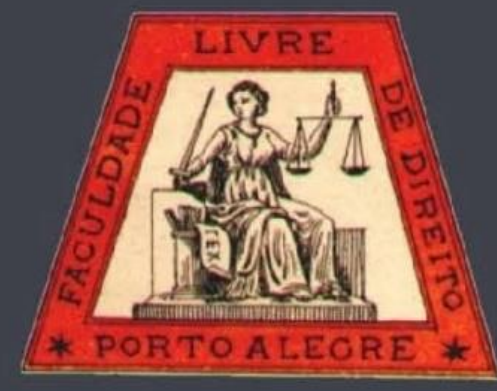

\title{
As práticas colaborativas como um recurso para as situações de divórcio
}

Collaborative practices as a resource for divorce situations

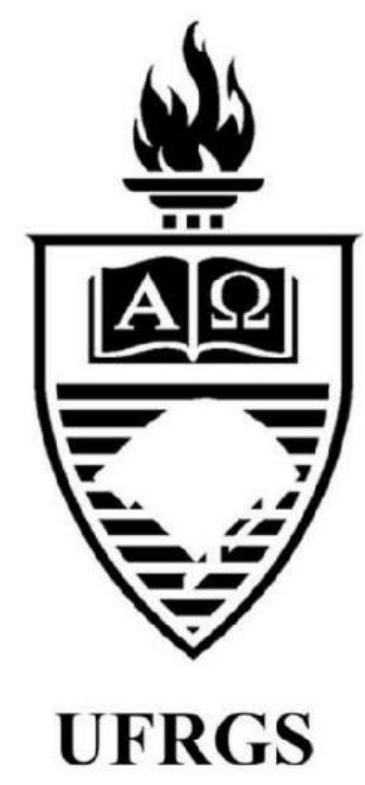

Eveline Gonçalves Denardi Escola Paulista de Direito

Isabel Cristina de Moura

Escola Paulista de Direito

Mariana Correa Fernandes

Escola Paulista de Direito 


\title{
As práticas colaborativas como um recurso para as situações de divórcio
}

\author{
Collaborative practices as a resource for divorce situations
}

\author{
Eveline Gonçalves Denardi* \\ Isabel Cristina de Moura** \\ Mariana Correa Fernandes ${ }^{* * *}$
}

\section{REFERÊNCIA}

DENARDI, Eveline Gonçalves; MOURA, Isabel Cristina de; FERNANDES, Mariana Correa. As práticas colaborativas como um recurso para as situações de divórcio. Revista da Faculdade de Direito da UFRGS, Porto Alegre, n. 36, vol. esp., p. 56-72, out. 2017.

\begin{abstract}
RESUMO
Este artigo propõe a utilização das Práticas Colaborativas como um procedimento apropriado para as situações de divórcio e seus desdobramentos. Nesse método extrajudicial de resolução de controvérsias, não adversarial e interdisciplinar, o processo decisório é construído de forma conjunta, articulando interesses por meio do diálogo. Dessa forma, a prática se pauta no protagonismo e na corresponsabilização das partes. As Práticas Colaborativas se apresentam como uma alternativa à litigiosidade e surgem em consonância com a política nacional de tratamento adequado de conflitos, na medida em que, além de buscarem acordos satisfatórios e duradouros, que otimizem recursos, cuidam das questões emocionais inerentes ao divórcio. Com isso, pais e filhos tendem a sofrer menos, pois constroem conjuntamente um relacionamento funcional para após a ruptura.
\end{abstract}

\section{PALAVRAS-CHAVE}

Família. Práticas Colaborativas. Autocomposição. Preservação dos filhos.

\section{ABSTRACT}

This paper proposes the use of Collaborative Practices as the appropriate procedure for divorces and their developments. In this a non-adversarial, interdisciplinary, and extrajuducial method of resolving disputes, the decision-making process is built jointly, articulating interests through dialogue. This way, this type of practice is based on protagonism and co-responsability of the parties. An alternative to litigation is presented, in accordance with the national policy of appropriate conflict management, as, in addition to seeking satisfactory and long-lasting agreements that optimize resources, these deal with the emotional issues inherent in divorce. Thus, parents and children tend to suffer less, since a functional relationship is built together after the breakup.

\section{KEYWORDS}

Divórcio. Family. Collaborative Practices. Divorce. Autocomposition. Protection of children.

\footnotetext{
* Professora da pós-graduação (mestrado) na Escola Paulista de Direito (EPD), na disciplina Metodologia de Pesquisa e Ensino do Direito. Doutora (2012) e Mestre (2007) em Direito do Estado (Direito Constitucional) pela Pontifícia Universidade Católica de São Paulo (PUC-SP). Bacharel em Jornalismo (1998) e Direito (2004) pela PUC-SP. Pesquisadora do CNPq pelo Núcleo Dignidade Humana e Garantias Fundamentais na Democracia, da Faculdade de Direito da PUC-SP. Editora jurídica na Editora Saraiva/Somos Educação.

${ }^{* *}$ Advogada Colaborativa e Mediadora de Conflitos. Mestranda em Direito pela Escola Paulista de Direito - EPD/SP, área de concentração em soluções alternativas de controvérsias empresariais. Integrante do Instituto Brasileiro de Práticas Colaborativas (IBPC). Especialista em Direito Cível e em Direito de Família e Sucessões. Coordenadora adjunta da Comissão de Práticas Colaborativas do IBDFAM/RS. Membro da Comissão Especial de Mediação e Práticas Restaurativas da OAB/RS.

*** Advogada Colaborativa e Mediadora de Conflitos. Mestranda em Direito pela Escola Paulista de Direito - EPD/SP, área de concentração em soluções alternativas de controvérsias empresariais. Integrante do Instituto Brasileiro de Práticas Colaborativas (IBPC). Coordenadora da Comissão de Práticas Colaborativas do IBDFAM/RS. Membro da Comissão Especial de Mediação e Práticas Restaurativas da OAB/RS.
} 


\section{SUMÁRIO}

Introdução. 1. O divórcio como um fenômeno multifatorial. 2. Práticas colaborativas: uma nova abordagem. 3. Formação da equipe multidisciplinar. 3.1. Advogado colaborativo. 3.2. Coach (Profissional de saúde mental). 3.3. Neutro financeiro. 3.4. Especialista infantil. Conclusão. Referências.

\section{INTRODUÇÃO}

Quando o desfazimento do vínculo conjugal se impõe, é necessário adotar uma série de medidas para minimizar os impactos dessa nova realidade na vida de todos os envolvidos. $\mathrm{O}$ caminho mais comum - porém, o menos recomendável sob a perspectiva deste estudo - é o da judicialização, que sempre atribui a um terceiro a tarefa de decidir sobre os rumos da situação, potencializando desta forma o conflito já existente entre os cônjuges.

O litígio parece não ser a melhor solução para os conflitos gerados pelo rompimento e as questões referentes à reorganização da vida familiar. As sentenças daí decorrentes são proferidas dentro de molduras legais que não dão conta dos anseios e necessidades de todos os envolvidos.

Este artigo visa enfrentar, sob vários aspectos, os problemas envolvidos neste delicado momento familiar, enfatizando a relevância de uma alternativa viável à judicialização: as práticas colaborativas.

Baseado na premissa de que os conflitos familiares são fenômenos multifatoriais, o artigo elege as práticas colaborativas para enfatizar uma nova forma de lidar com a situação. Trata-se de um método extrajudicial de resolução de controvérsias, não adversarial e interdisciplinar, focada exclusivamente na construção conjunta dos processos decisórios por meio do diálogo. É pautada especialmente no protagonismo e na corresponsabilização das partes.

O breve estudo aqui apresentado pretende demonstrar que esta prática internacional se expandiu a partir de 2011 dentre profissionais brasileiros, especialmente do RJ e SP, que passaram a adotar a metodologia.

Neste estudo, serão aprofundados os conhecimentos teóricos envolvidos no conceito das práticas colaborativas e a maneira como podem ser incorporados à nossa cultura.

As práticas colaborativas - utilizadas principalmente em situações de conflitos crônicos, onde há forte carga emocional - têm como principal objetivo preservar os vínculos afetivos e o desenvolvimento de habilidades comunicacionais.

O texto investiga como ocorrem atualmente as práticas colaborativas e ressalta a necessidade de juízes e promotores conhecerem os princípios nela envolvidos.

Por exigir a formação de uma equipe multidisciplinar, observa-se como a prática é formada e os critérios eleitos para a escolha dos profissionais que atenderão às famílias envolvidas.

Imprescindível, neste contexto, traçar o perfil do advogado colaborativo. $\mathrm{O}$ artigo revela que o advogado hoje está muito mais ligado à sua atividade estritamente técnica (e especialmente processual) do que efetivamente ligado ao assessoramento de pessoas em processo de transição. Permanece, ainda, a cultura de que um ganha e o outro perde.

No entanto, cada vez mais, eles têm sido exigidos a conhecerem os métodos extrajudiciais, oferecendo aos seus clientes novos caminhos e ampliando seu leque de atuação para além de um processo judicial na resolução dos conflitos.

O texto explora essa ideia demonstrando que, ao se adotar as práticas colaborativas, a lei passa a ser apenas um importante parâmetro 
balizador, e não a protagonista do processo, para a qual todas as decisões são voltadas.

Discute-se, especialmente, os fatores que devem ser considerados no processo, muitos de âmbito emocional, dentre eles, as necessidades de cada envolvido, o senso de justiça, as realidades prática e econômica, os acordos prévios e os fatores culturais e emocionais de cada cliente, que passam a receber igual consideração.

Ao final, destaca-se nas práticas colaborativas a atuação de profissionais especializados extremamente relevantes durante todo o contexto do divórcio. O papel destes profissionais é colaborar lidando com as consequências do desfazimento do vínculo conjugal que reverberam em outras esferas da vida do indivíduo.

Neste contexto destacam-se o profissional de saúde mental (auxilia na reorganização de forma saudável e na preservação dos vínculos, sempre mantendo um enfoque prospectivo), o profissional especializado em finanças (as alterações financeiras que atingem o casal durante o processo e após o divórcio legal demandam reeducação financeira) e um especialista em crianças (sua característica principal é trazer os interesses das crianças à negociação de forma indireta, evitando que necessitem participar pessoalmente do processo, o que poderia ser extremamente traumático para elas).

Tendo em vista a complexidade da situação eleita para análise neste artigo, demonstra-se que as práticas colaborativas são um recurso muito rico quando considerados todos os múltiplos aspectos os quais é capaz de atender a partir de sua perspectiva interdisciplinar na situação do

\footnotetext{
${ }^{1}$ Pesquisa Estatísticas do Registro Civil 2014. Instituto Brasileiro de Geografia e Estatística (IBGE). Disponível em: $<$ http://www.brasil.gov.br/cidadania-ejustica/2015/11/em-10-anos-taxa-de-divorcios-crescemais-de-160-no-pais >. Acesso em: 01 abr.2017.

2 TESLER, Pauline; THOMPSON, Peggy. Collaborative divorce - the revolutionary new way to restructure your
}

desfazimento do vínculo matrimonial e suas implicações no âmbito familiar.

\section{O DIVÓRCIO COMO UM FENÔMENO MULTIFATORIAL}

Apesar do clássico "ninguém casa pensando em um dia se separar”, o índice de divórcios no Brasil teve um aumento de 161,4\% em dez anos (de 2004 a 2014) ${ }^{1}$, o que demonstra que esse é um acontecimento estatisticamente natural em nosso país.

A sociedade, contudo, ainda perpetua mitos que romantizam o casamento à la "até que a morte nos separe" e demonizam o processo de divórcio, transformando seu ex-cônjuge no seu maior rival agravando um dos momentos mais difíceis pelo qual uma pessoa pode passar ${ }^{2}$.

Segundo a escala de Holmes e Rahe ${ }^{3}$ de eventos estressantes de vida, o divórcio vem em segundo lugar, depois somente da morte de um dos cônjuges. Em razão disso, é perfeitamente normal que se vivencie uma ampla gama de emoções e, nesse momento de turbulência, onde precisam tomar decisões importantes acerca do rompimento, tenham suas habilidades de fazerem boas escolhas limitadas.

Tristeza, culpa, vergonha e sensação de fracasso são exemplos de reações normais ao fim de um relacionamento amoroso, mas que podem tornar o processo todo muito mais difícil. Estudos revelam que o sistema familiar precisa, em média, de 1 a 3 anos para lidar com o divórcio, se reestabilizar e seguir seu desenvolvimento em uma nova configuração ${ }^{4}$.

Importante ter clareza de que quando se fala em estabilização do sistema familiar não se está

family, resolve legal issues and move on with your life. New York: Harper Collins, 2007.

${ }^{3}$ ESCALA de Holmes-Rahe para avaliação do estresse. Disponível em: <http://nenossolar.com.br>. Acesso em: 29 abr. 2016.

${ }^{4}$ CARTER, Betty; McGOLDRICK, Monica. As mudanças no ciclo de vida familiar. Porto Alegre: Artes Médicas, 1995. 
restringindo os impactos do divórcio somente ao casal, mas a todos os membros da família, que se relacionam de forma sistêmica, com diferentes partes em interação. Parentes próximos e amigos podem ser significativamente impactados pela decisão de separação tomada por um casal, ainda que não existam filhos envolvidos.

O divórcio, sendo um recorte na linha existencial do casal, é uma situação desafiadora para todos os envolvidos. Em razão do turbilhão de sentimentos (e influências) que enfrentam neste período, os casais por vezes optam por distanciar-se um do outro e encontram a necessidade de repassar responsabilidades a um juiz para que, em seu nome, tome as decisões que surgem do rompimento.

Ao juiz restaria manifestar-se nos limites do âmbito jurídico, a respeito de um processo nascido pela distorção das emoções dos envolvidos e que, por isso, por mais coerentemente que decida, não irá satisfazê-los em seus reais interesses. Inocente seria pensar que todas as emoções que permeiam o contexto do divórcio, contudo, iriam se resolver com a propositura de uma demanda judicial.

$\mathrm{Na}$ tentativa de aliviar sua dor e culpar o exparceiro por toda a frustração do fim do casamento, a busca por uma sentença de procedência no Poder Judiciário, acaba por potencializar o conflito existente entre os cônjuges. Responsabilizar somente o outro parece reduzir o sofrimento a curto prazo e soa como uma saída mais atraente do que reconhecer a sua parcela de participação no fim da união. Nesse sentido, Monica Lobo refere que "as relações se constroem pela participação de dois ou mais indivíduos e se desconstroem por contribuição, ativa e ou passiva, de todos os envolvidos no contexto fático". 5

\footnotetext{
${ }^{5}$ LOBO, Monica; PELAJO, Samantha. Mediação familiar: algumas premissas emocionais e jurídicas. In: ALMEIDA, Tania. Mediação de conflitos: para iniciantes, praticantes $e$ docentes. Salvador: JusPodivm, 2016. p.443-455.
}

Geralmente esses processos instalam uma "verdadeira guerra" entre os cônjuges. E no confronto de um contra o outro, todos perdem.

O litígio parece não ser a melhor solução para os conflitos gerados pelo rompimento e as questões referentes à reorganização da vida familiar. As sentenças daí decorrentes são proferidas dentro de molduras legais que não dão conta dos anseios e necessidades de todos os envolvidos.

\section{PRÁticAS COLABORATIVAS: UMA NOVA ABORDAGEM}

Constatando a ineficácia dos processos judiciais para a atenção das expectativas dos seus clientes e a ausência de satisfação, mesmo com o ganho das causas, Stuart Webb, advogado americano da área de família, decidiu restringir sua atuação somente à fase negocial, pois compreendeu que poderia utilizar seus conhecimentos de forma diferente. No início da década de 90, redigiu uma carta comunicando o novo perfil aos colegas, magistrados e clientes, deixando claro que se retiraria do caso, se inviável o acordo ${ }^{6}$.

Em efeito cascata, outros colegas foram aderindo a esta forma de atuação e os clientes, por sua vez, passaram a buscar este serviço. Anos mais tarde, a psicóloga Peggy Thompson e a advogada Pauline Tesler, compreendendo que não bastava apenas o olhar não adversarial para atender os diferentes aspectos que revestiam as situações vividas pelas pessoas, ampliaram esta ideia, incluindo outros profissionais na rede de

\footnotetext{
${ }^{6}$ FÜRST, Olívia. Práticas colaborativas: novos paradigmas do Direito. In: MARODIN, Marilene; MOLINARI, Fernanda. Mediação de conflitos: Paradigmas contemporâneos e fundamentos para a prática. Porto Alegre: Imprensa Livre, 2016. p. 71-86.
} 
atendimento, a partir do reconhecimento de que o conflito é um fenômeno multifatorial ${ }^{7}$.

Assim, complementando o rol de possibilidades no campo das resoluções consensuais de controvérsias até então existentes, surgem as práticas colaborativas.

As práticas colaborativas são um método extrajudicial de resolução de controvérsias, não adversarial e interdisciplinar. Focada com exclusividade na construção conjunta dos processos decisórios por meio do diálogo, a prática se pauta no protagonismo e na corresponsabilização das partes.

Três profissionais brasileiras de diferentes áreas, Tania Almeida (médica), Fernanda Paiva (advogada) e Flavia Soeiro (advogada) tiveram contato com o método nos Estados Unidos. Em seu retorno ao Brasil, divulgaram a metodologia. A partir disso, no ano de 2011, formaram-se grupos de estudos no Rio de Janeiro e em São Paulo, a fim de aprofundar os conhecimentos teóricos e trabalhar na incorporação do método à nossa cultura ${ }^{8}$.

Com o desenvolvimento e crescimento desta ideia, o grupo candidatou-se ao prêmio Innovare, onde foi vencedor do prêmio na categoria Advocacia. A partir daí a prática vem se popularizando e capacitações nacionais vêm sendo desenvolvidas em diversas partes do país ${ }^{9}$.

As práticas colaborativas têm como principal objetivo preservar os vínculos afetivos e o desenvolvimento de habilidades comunicacionais. É utilizada principalmente em situações de conflitos crônicos, onde há forte carga emocional. Apresentam-se como uma forma de resolução de conflitos mais rápida, mais

\footnotetext{
${ }^{7}$ FONKERT, Renata. A mediação e o divórcio colaborativo por equipe interdisciplinar nas situações de divórcio: um enfoque construcionista social e pósmoderno. In: ALMEIDA, Tania. Mediação de conflitos: para iniciantes, praticantes e docentes. Salvador: JusPodivm, 2016. p. 463

${ }^{8}$ Histórico das práticas colaborativas. Disponível em: http://praticascolaborativas.com.br/home/na-area-defamilia.php\#historico. Acesso em: 07 ago. 2017
}

econômica e com resultado mais eficaz e duradouro. Através deste procedimento os envolvidos - protagonistas de suas histórias - têm a oportunidade de encontrar uma solução que satisfaça a todos sem que haja um ganhador e um perdedor.

As Práticas Colaborativas se colocam lado a lado com os demais métodos consensuais de resolução de conflitos, mas dele se diferenciam. Nesse sentido, Olívia Fürst a diferencia da mediação de conflitos:

\begin{abstract}
A principal inovação está no fato de que a Prática Colaborativa combina ferramentas da Mediação com a essência da Advocacia. Em outras palavras: ela dota o profissional de técnicas e habilidades em negociação e comunicação, próprias da mediação; agrega a atuação de outros saberes na resolução do conflito desde o início do processo (equipe multidisciplinar); e não exige neutralidade e imparcialidade do profissional, mantendo o advogado atuando em consonância com o âmago de sua profissão, que é a defesa do melhor interesse do seu cliente ${ }^{10}$.
\end{abstract}

Como referido, o procedimento das práticas colaborativas ocorre integralmente fora do Poder Judiciário, sem qualquer intervenção deste durante o procedimento. Após finalizadas as negociações entre advogados colaborativos e de uma equipe multidisciplinar especificamente criada para aquela família, as combinações são reduzidas a termo e, sendo caso de necessária homologação judicial, são encaminhadas, em formato de acordo redigido conjuntamente por ambas as partes, ao Poder Judiciário para que, ouvido o Ministério Público, seja homologado.

Há extrema importância de que Juízes e Promotores de Justiça conheçam os princípios e

\footnotetext{
${ }^{9}$ Práticas colaborativas no Direito de Família. Disponível em:

<http://www.premioinnovare.com.br/praticas/l/praticascolaborativas-no-direito-de-familia> Aceso em: 07 ago 2017

${ }^{10}$ FÜRST, Olívia. Práticas Colaborativas no Direito de Família. Disponível em:

<https://docs.wixstatic.com/ugd/e910af_2dca64edbf73466 1b761e5f074dcf740.pdf> Acesso em: 07 ago. 2017
} 
funcionamento das Práticas Colaborativas, pois sua consolidação passa pelo reconhecimento destes das combinações realizadas por meio do procedimento. Nesse sentido, refere Olívia Fürst:

É de crucial importância que compreendam o trabalho que é realizado extrajudicialmente na construção colaborativa e multidisciplinar dos acordos familiares, onde cada palavra tem um significado especial e representa um equilíbrio sutil, imperceptível muitas vezes para aqueles que não vivenciaram o processo de diálogo ${ }^{11}$.

Atualmente, há profissionais colaborativos em 11 diferentes estados da federação. Estes profissionais têm lutado para difundir o uso das práticas colaborativas em suas regiões. Como as práticas colaborativas se dão em âmbito totalmente extrajudicial e a confidencialidade é princípio basilar dessa metodologia, não é possível precisar quantos casos tem sido resolvidos por meio do seu uso. Somente é possível referir o crescimento do interesse por parte dos profissionais e dos clientes.

\section{FORMAÇÃO DA EQUIPE MULTIDISCIPLINAR}

Sendo o divórcio um evento multifatorial, nas práticas colaborativas uma equipe multidisciplinar personalizada é formada com o intuito de auxiliar as pessoas a atravessarem esse momento delicado de rompimento e a definir as questões importantes a serem resolvidas. Com a criação de um ambiente protegido e produtivo onde o diálogo seja viável, são incentivadas a desenvolverem suas habilidades comunicacionais, reorganizarem seus papéis e a produzirem opções que atendam a interesses mútuos.

A composição da equipe é construída com o cliente, de modo personalizado, atendendo às necessidades específicas de cada família, o que

\footnotetext{
${ }^{11}$ FÜRST, Olívia. Práticas Colaborativas no Direito de Família. Disponível em:
}

enfatiza o protagonismo e a autonomia. Enquanto a participação de dois advogados (um para cada parte) é imprescindível, outros profissionais são incluídos sempre que a qualidade do poder decisório for melhor com o auxílio deles.

Toda equipe que atua no contexto colaborativo é capacitada nesta metodologia, a fim de que possa atuar de forma diferenciada, reconhecendo o momento de vida pelo qual passam os envolvidos e auxiliando-os na construção de consenso em situações complexas e de difícil resolução.

Ao exercerem sua voluntariedade, os clientes têm a possibilidade de escolher quais profissionais, daqueles capacitados, gostariam que os acompanhassem.

Como meio de proteção da natureza extrajudicial da prática, todos assinam um termo de confidencialidade e não litigância, que garante o sigilo das negociações, o não ingresso no Poder Judiciário por parte dos advogados e a não participação em eventuais processos judiciais pelos profissionais colaborativos. Esse pacto garante um espaço blindado, livre de ameaças, pautado pelo diálogo e pelo comprometimento entre as partes.

Os conflitos possuem naturezas múltiplas, portanto a visão não pode ser limitada a um só ângulo ou aspecto da questão. Isto demonstra especial adequação de um procedimento interdisciplinar, que possibilita não somente reunir diferentes saberes, mas disciplinas que conversam entre si.

Os desdobramentos do divórcio são numerosos, não ficam restritos aos seus reflexos nos mundos jurídico, econômico, emocional ou comunitário separadamente. O fim do compromisso representa um conjunto de todas essas repercussões, por isso, é necessária a atuação de uma equipe que respeite as múltiplas

<https://docs.wixstatic.com/ugd/e910af_2dca64edbf73466 1b761e5f074dcf740.pdf> Acesso em: 07 ago. 2017 
facetas de cada família e permita o seu desenvolvimento funcional.

\subsection{Advogado colaborativo}

Analisar o papel do advogado nas Práticas Colaborativas é remeter-se à sua função original de resolvedor de problemas e conhecedor das leis. Hoje o seu papel, mesmo quando da área familiar, está muito mais ligado à sua atividade estritamente técnica (e especialmente processual) do que efetivamente ligado ao assessoramento de pessoas em processo de transição.

Cada vez mais os advogados têm sido exigidos a conhecerem os métodos extrajudiciais, oferecendo aos seus clientes novos caminhos e ampliando seu leque de atuação para além de um processo judicial na resolução dos conflitos. Essa postura se alinha com o previsto no Código de Ética e Disciplina da Ordem dos Advogados do Brasil (OAB), em seu art. $2^{\circ}$, inciso VI: “é dever do advogado prevenir sempre que possível a instauração de processos judiciais"12.

Essa abordagem remodela a advocacia, fazendo com que os profissionais trabalhem em conjunto e não mais um contra o outro, abandonando a busca por uma solução perdeganha, para priorizar acordos de benefícios mútuos. O advogado deixa de olhar o cliente sozinho, mas passa a olhar a família como um todo, reconhecendo que para que os interesses do seu cliente estejam atendidos, os interesses dos demais envolvidos precisam estar igualmente atendidos.

A postura parcial que se espera de um defensor, todavia, não afeta a postura colaborativa necessária ao funcionamento do procedimento, pois conforme ressalta Monica Gama:

${ }^{12}$ ORDEM DOS ADVOGADOS DO BRASIL. Resolução $\mathrm{n}^{\circ}$ 02, de 19 de outubro de 2015. Aprova o Código de Ética e Disciplina da Ordem dos Advogados Brasileiros. Disponível em: <http://www.oab.org.br/arquivos/resolucao-n-022015-ced2030601765.pdf >. Acesso em: 29 abr. 2016.
A parcialidade e a colaboratividade podem andar juntas, lado a lado, partindo da premissa que o advogado vai atuar sempre de modo a respeitar e defender os interesses de seu cliente, porém, levando-se em conta que a maneira de negociação entre as partes deve atender aos princípios estabelecidos pelo processo colaborativo ${ }^{13}$.

A maioria dos advogados, receando uma perspectiva de alinhamento com o cliente da parte contrária, acaba optando por soluções onde o seu cliente seja o "ganhador" e o outro, o "adversário", seja o "perdedor". Na vã tentativa de poupar quem o contrata, por vezes "tomam para si” a situação e afastam o real interessado do processo decisório sem refletir sobre a dimensão do impacto que essa postura pode ter posteriormente na família dele.

O advogado colaborativo dá um passo atrás, entende que o cliente está inserido em um contexto maior e compreende que é ele o verdadeiro protagonista de sua história. Assim, reconhecendo que somente cuida dos interesses deste na medida em que preserva os interesses de toda a família, os acordos só são negociados na presença das partes.

A relação entre os advogados, quando estes atuam de forma colaborativa, é de boa-fé e de parceria, pois deixam de representar uma ameaça mútua, já que a assinatura do termo de não litigância os impede de atuar de forma litigiosa, nesse caso específico, se o divórcio colaborativo não tiver êxito. Os profissionais estão autorizados a usar, quando necessário, conjuntamente, o Poder Judiciário apenas para homologar os acordos construídos entre as partes.

É dever do advogado garantir a transparência desse ambiente, auxiliando o

13 GAMA, Monica Ribeiro de Andrade. Práticas colaborativas: uma nova forma de advocacia que combina parcialidade e colaboração. Disponível em: $<$ http://praticascolaborativas.com.br/home/artigo.php?codi go=51>. Acesso em: 25 mar. 2017. 
envolvido a entender o que o motiva, quais os seus direitos e deveres, bem como os do outro, a fim de tornar a negociação mais compreendida e favorecer a construção informada de soluções.

Como a negociação é pautada nos interesses de cada cliente, a lei deixa de limitar o resultado e passa a ser somente um parâmetro balizador. Outros pontos de referência, que incluem, por exemplo, as necessidades, o senso de justiça, as realidades prática e econômica, os acordos prévios, os fatores culturais e emocionais de cada cliente passam a receber igual consideração.

A transparência exigida das partes inclui a ideia de não reter ou deturpar informações e documentos importantes relativos ao processo colaborativo ou agir de forma a conscientemente minar ou aproveitar-se das negociações. Os profissionais jurídicos são centrais nas práticas colaborativas e devem ter uma atuação pautada no comprometimento com esse novo formato.

\subsection{Coach (Profissional de saúde mental)}

Assim como o casamento é mais do que "uma folha de papel”, o processo de divórcio representa muito mais do que a assinatura no acordo final. A ruptura não implica somente no afeto, mas representa a frustração de planos, sonhos e projetos comuns. Essa perda, em diversos níveis, impacta na estrutura de segurança e estabilidade até então presentes naquela família.

A presença da alta carga emocional que se desenvolve durante esse período de transição na família, por vezes exige a participação de um terceiro que dê conta das questões emocionais ligadas ao fim do relacionamento. Nas práticas colaborativas, se possibilita a atuação de um profissional da área de saúde mental que auxilie na reorganização de forma saudável e na preservação dos vínculos, sempre mantendo um enfoque prospectivo.

Esse profissional vem sendo denominado nacionalmente como coach, a partir da utilização do mesmo termo em padrões internacionais. Neste contexto, além de formação na área da saúde mental e capacitação em práticas colaborativas, o coach precisa ter amplo conhecimento nas dinâmicas de família, do divórcio e do comportamento humano em situações de crise.

Ainda que se exija do profissional conhecimento em técnicas terapêuticas, sua atuação durante o procedimento colaborativo não é considerado terapia. A prática da terapia se diferencia na medida em que "o terapeuta o ajuda a desfazer suas malas e examinar e classificar o seu conteúdo. O profissional de divórcio ajuda você a carregar suas malas de um lado para o outro da rua".

$\mathrm{O}$ foco da atividade do coach que atua em práticas colaborativas não é o de reparar os danos causados pelo processo de divórcio, mas auxiliar o desenvolvimento de habilidades para lidarem com a negociação e a reconstrução de sua vida após a ruptura.

Os casais que tiverem filhos são auxiliados por esse profissional a separarem o papel conjugal do parental a fim de criarem um novo plano parental no qual sejam corresponsáveis pelo desenvolvimento e bem-estar dos filhos. Cada um dos envolvidos tem o seu coach, que atua de forma parcial sem perder o enfoque sistêmico.

A condução do trabalho é breve, focada nas questões relativas ao divórcio e se desenvolve de modo diverso do trabalho de um terapeuta pessoal, por isso, não é possível que este profissional seja aquele que já mantém ou venha a manter relação continuada com o cliente.

O profissional de saúde mental que atua em práticas colaborativas auxilia o cliente na fase de concretização do divórcio. Não é ele o mesmo profissional que o auxiliará frente às demais questões emocionais de sua vida. O suporte emocional é dado ao cliente com dificuldade apenas no que tange a esse período de transição, ainda que sugira tratamento psicológico com 
outro terapeuta. Portanto, a relação cliente-coach se encerra com o fim do divórcio colaborativo, podendo retornar somente em situações relativas à separação.

O desafio no processo de divórcio colaborativo é o de ajudar o envolvido a perceber as dificuldades pessoais que emergem neste momento, informando-o sobre o que esperar neste período de mudança; auxiliá-lo na identificação de posturas que impactam o outro cônjuge e assisti-lo na criação de um plano parental funcional e adequado, se for o caso. Com orientação sistêmica, esse profissional não visa encontrar um vilão ou uma causa aparente para o rompimento, mas, enxergando os familiares como elementos interconectados, promover a mudança de padrões de interação e possibilitar que, independentemente da configuração familiar, haja exercício apropriado da coparentalidade.

Romper a relação conjugal não coloca fim aos laços parentais (nem extingue a família). Ocorre uma reorganização familiar que impõe aos genitores a necessidade de estabelecerem um diálogo, a fim de que, priorizando o convívio familiar, possam superar suas diferenças e assegurar o direito dos filhos de crescerem com a presença de ambos em suas vidas.

Os clientes, imersos em um mar de sentimentos, por vezes encontram-se inseguros e ansiosos quanto ao que virá pela frente. Nessa situação, o coach se coloca ao seu lado, assessorando-o no fortalecimento emocional necessário para enfrentar as incertezas dessa etapa.

Além de ser necessário ao bom desenvolvimento das negociações entre as partes a partir do treinamento individual das competências necessárias ao diálogo, o profissional é fundamental para o funcionamento da equipe multidisciplinar. Os advogados dão ao coach um maior entendimento dos aspectos legais que revestem o divórcio, ao passo que o profissional de saúde mental os auxilia a compreender o momento e as repercussões emocionais desse evento na vida daquele cliente.

Assim, o profissional da saúde mental, como parte da equipe, tem, como os demais, a missão de trabalhar de forma interdisciplinar, compartilhando informações, para que diferentes formas de enxergar aquela situação componham uma figura com mais cores. No exercício das práticas colaborativas a equipe trabalha de forma interdisciplinar, visando atender à multifatorialidade do conflito e as necessidades personalizadas das famílias.

A autonomia privada e a ideia de suporte aos envolvidos em uma situação conflitiva, que permeiam todo o procedimento colaborativo, novamente aparecem em destaque quando se pensa na duração da intervenção do coach. Profissional e cliente podem juntos analisar, diante das evoluções que houver no curso dos atendimentos, a pertinência dessa participação durante o restante do processo.

Alguns sinais como o desenho do plano parental ou uma significativa melhora na comunicação em reuniões com ambos os envolvidos podem indicar que é o momento de interromper a participação do profissional de saúde mental.

Novas situações podem surgir exigindo nova intervenção pontual para tratar de assuntos específicos relacionados ao divórcio, mesmo após o fim do procedimento colaborativo, para o que os coaches precisam estar preparados e disponíveis.

A ideia não é a de que haverá direcionamento do cliente, mas através de técnicas específicas seja provocada a reflexão quanto ao que esperar do futuro em âmbito pessoal e parental, não ficando limitados aos seus papéis enquanto pais. $\mathrm{O}$ tom dado à construção dessa nova realidade deve ser marcado por uma visão prospectiva, na qual seja possível construir uma nova realidade após o fim do vínculo conjugal. 


\subsection{Neutro financeiro}

Além do divórcio legal, desenvolve-se o divórcio econômico, uma situação que pode gerar muita angústia e desespero em razão da diminuição dos recursos financeiros de todos os envolvidos.

Diante desse grande desafio de reestruturar a vida financeira no momento pós-divórcio, pode ser necessário um auxílio especializado voltado às questões econômicas. Incluído mediante as necessidades específicas de cada caso, o neutro financeiro é o profissional com conhecimento nas áreas de economia, administração, finanças ou contabilidade capaz de considerar os desdobramentos financeiros do divórcio.

Os envolvidos escolhem conjuntamente quem os auxiliará nas questões relativas às finanças, $o$ que novamente evidencia $o$ protagonismo dos clientes no procedimento colaborativo. Feita a escolha, as partes são estimuladas pelo próprio procedimento a serem autônomas e corresponsáveis por suas decisões.

$\mathrm{O}$ termo neutro financeiro vem de suas próprias atribuições: neutro por trabalhar para ambos, de modo imparcial, diversamente dos demais profissionais da equipe, que, embora enxerguem a família de forma sistêmica, atuam de forma parcial em relação a quem os contratou e financeiro por buscar o equilíbrio entre os clientes, por meio da informação técnica financeira, que equaliza as diferenças e cria uma situação mais igualitária.

Casais se divorciando muito frequentemente desconhecem as implicações econômicas decorrentes dessa decisão e encarar essa realidade pode ser bastante difícil. Por isso, além de conhecimentos técnicos das mencionadas áreas, o profissional que atuará em casos colaborativos precisa estar preparado, por meio de capacitação em práticas colaborativas, para lidar com situações nas quais a comunicação esteja bastante frágil e permeada por emoções diversas.
Assim, o início da abordagem se dá com a verificação dos interesses, objetivos e expectativa dos clientes que podem influenciar o trabalho. De forma transparente, é feito um levantamento da realidade financeira e patrimonial da família, pois um entendimento completo da situação irá facilitar a interação adequada com e entre eles.

$\mathrm{O}$ neutro financeiro assessora as partes, reunindo informações sobre a situação econômica atual, a fim de possibilitar propostas com menor incidência de carga tributária. A partir da análise de cenários, elaboração de planilhas e orçamentos o profissional pode sugerir formas de gerir os recursos existentes, evitando perdas financeiras previsíveis e garantindo a otimização dos recursos de todos.

O trabalho dos especialistas em finanças no processo colaborativo não é o de planejadores, ainda que boa parte deles sejam certificados para tanto. Assim como no caso da terapia versus o papel do coach, o planejador financeiro tem uma delimitação de trabalho diferente daquele realizado pelo neutro financeiro, cuja atuação é pontual e temporária, com vistas a equiparar os clientes para tomarem decisões qualificadas e alcançarem sua independência.

O especialista em finanças tem intervenção de natureza breve, tal qual o profissional de saúde mental. Desta forma, é necessário que este não tenha relação prévia ou futura com os clientes. Essa independência é ainda mais cristalina no caso do neutro financeiro devido à credibilidade que lhe é atribuída em razão da sua condição de neutralidade.

Outra função de destaque do profissional que auxilia no cuidado econômico é o de educador. Cabe a este oferecer educação financeira a um ou a ambos os clientes, na medida da sua necessidade, para que possam ultrapassar as barreiras do desconhecimento e tornar a tomada de decisão um passo mais suave na criação de um futuro acordo com benefícios mútuos. 
As peculiaridades de cada família com relação à distribuição de tarefas podem exigir que um dos clientes necessite de especial atenção para reconhecer sua posição financeira atual e desenvolver novas competências de gestão financeira. Esse trabalho, ainda que realizado somente com um dos cônjuges, não prejudica o caráter imparcial da atividade, pois exige a concordância de todos.

Devido ao caráter interdisciplinar, pautado na boa-fé e na transparência do divórcio colaborativo, toda a informação compartilhada pelos clientes deve ser dividida com os demais membros da equipe.

Ao encontrarem-se conjuntamente e com o seu especialista em finanças, o casal em separação tem a oportunidade de revisar informações de forma coletiva, fazer perguntas, resolver malentendidos e reduzir desconfianças, o que tende a nivelar os conhecimentos financeiros, neutralizar possíveis intimidações e promover equilíbrio de poder.

O divórcio provoca uma diminuição do padrão de vida da família, pois os rendimentos que eram destinados à manutenção de uma só residência, passarão a ser utilizados para amparar duas diferentes. Essa mudança de realidade exige que os pais criem novas maneiras de satisfazer as necessidades financeiras dos seus filhos, que permanecem inalteradas.

Como parte da equipe colaborativa, o neutro financeiro poderá participar de reuniões conjuntas ou somente com os clientes (preferencialmente com os dois), inclusive com a possibilidade de demandar a presença dos coaches para apresentar algum cenário financeiro no qual verifique demasiada fragilidade, no intuito de instrumentalizar as partes para que no futuro possam alcançar sua autonomia.

\footnotetext{
${ }^{14}$ ESTROUGO, Mônica Guazzelli. Litígio de família: quem protege as crianças? In: (Orgs.) AZAMBUJA, Maria Regina Fay de; SILVEIRA, Maritana Viana; BRUNO,
}

\subsection{Especialista infantil}

Divórcios mal resolvidos têm como principais prejudicados os filhos. Por óbvio, não se pode idealizar uma separação em que a criança seja totalmente poupada, já que elas integram o sistema familiar e, por isso, sofrem com a alteração dos demais elementos ${ }^{14}$.

Para preservar os filhos e possibilitar sua participação de forma protegida, um especialista em desenvolvimento de crianças e adolescentes irá auxiliar os pais a compreenderem o momento dos filhos nesse processo de ruptura conjugal.

O profissional não é parcial em relação aos clientes, mas se alinha com a perspectiva dos filhos, razão pela qual não pode ser considerado (ao menos tão) neutro quanto o financeiro. Sua característica principal é a de trazer os interesses das crianças à negociação de forma indireta, evitando que necessitem participar pessoalmente do processo, o que poderia ser extremamente traumático para elas.

O especialista em crianças é um licenciado em saúde mental com treino e experiência em sistemas familiares, desenvolvimento infantil e práticas colaborativas. Assim, pode possibilitar a construção de um ambiente seguro e sigiloso para que os filhos possam fazer perguntas e compartilhar sentimentos e necessidades.

Esses profissionais é que garantirão que as questões emocionais das crianças sejam consideradas pelos pais e demais membros da equipe. Somente assim poderá assegurar-se de que todos trabalharão na construção de um plano parental responsável e adequado àquelas crianças, afastando-se da ideia de que existe um "molde" que configure o ideal para cada família.

Quando o especialista em desenvolvimento infantil participa das reuniões com os pais, trabalha em conjunto com os coaches, que

Denise Duarte. Infância em família: um compromisso de todos. Porto Alegre: IBDFAM, 2004, p. 169-170. 
igualmente se esforçarão para fortalecer as responsabilidades parentais, mesmo com o fim da relação conjugal dos genitores. Acordos que trabalham a alteração da estrutura familiar considerando a visão das crianças e a peculiaridade da realidade de cada um dos pais são mais equilibrados e têm maior adesão por todos os envolvidos.

Nem sempre é possível identificar a necessidade de um especialista infantil nos momentos iniciais de um divórcio colaborativo, mas isso não impede sua inclusão posteriormente. Por ser esse procedimento adaptado à realidade de cada família, esse profissional pode compor a equipe a qualquer momento e ser escolhido pelas partes conjuntamente.

A atuação do especialista infantil é breve e pontual, não podendo - assim como os demais profissionais da equipe - manter relacionamento com os clientes. O profissional tem somente o contato necessário com a criança, afastando-se do papel de terapeuta.

Os olhares trazidos são informativos, ajudando os pais a pensarem nos filhos como sujeitos para que estes tomem as decisões que julgarem mais adequadas, não ficando adstritos às percepções deste profissional. Como diferem da natureza de pareceristas, os especialistas comunicam-se em reunião, de forma oral, preferencialmente na presença de ambos os genitores.

As informações prestadas pelos especialistas em desenvolvimento de crianças podem alterar muito o rumo das negociações, por serem muito delicadas. A partir da identificação de temas sensíveis o time pode concluir ser positivo a presença de coaches para essa

\footnotetext{
15 FERRARINI, Letícia; MARCANTÔNIO, Roberta. A mediação familiar para casos de guarda compartilhada: a reafirmação da implementação do instituto no dissenso. In: (Orgs.) ROSA, Conrado Paulino da; THOMÉ, Liane Maria Busnello. Um presente para construir o futuro: diálogos sobre família e sucessões. Porto Alegre: IBDFAM/RS, 2015, p. 316.
}

conversa, reduzindo as chances de interpretações equivocadas.

É preciso compreender que os vínculos parentais não são cortados e nem abolidos. Eles apenas se transformam com o fim do vínculo conjugal. Assim, os pais devem administrar o desfazimento da sua relação visando promover a harmonia do convívio um com o outro em benefício dos filhos ${ }^{15}$.

Segundo Anna Oliverio Ferraris, as crianças precisam de estabilidade e pontos de referência claros e facilmente identificáveis ${ }^{16}$.

Em razão disso, fica claro que é fundamental a manutenção do convívio da criança com ambos os pais para que o seu desenvolvimento seja plenamente saudável. Neste âmbito as práticas colaborativas são uma alternativa possível para auxiliar a reconstruir e potencializar os laços parentais.

\section{CONCLUSÃO}

A partir do estudo das práticas colaborativas enquanto meio de solução de controvérsias relativas ao divórcio conclui-se que este é um recurso muito rico quando levamos em consideração os múltiplos aspectos os quais é capaz de atender a partir de sua perspectiva interdisciplinar. $\mathrm{O}$ enorme potencial deste instrumento se evidencia diante dos seus benefícios na elaboração e nos desdobramentos do divórcio.

É preciso avançar à ideia de que o rompimento nem sempre é um mau resultado para casais em sofrimento, não obstante os planos imaginados quando da união do casal.

16 FERRARIS, Anna Oliverio. Filhos de famílias divorciadas e reconstituídas: Identidade e história familiar. In: ANDOLFI, Maurizio. A crise do casal: uma perspectiva sistêmico-relacional. Porto Alegre: Artmed, 2002, p. 249263. 
Compreender que o divórcio é permeado por fortes emoções que podem gerar melhores ou piores consequências, a partir das escolhas feitas em um momento de desesperança, reflete a importância de uma equipe multidisciplinar quando da tomada de decisão. Decisões apoiadas e bem informadas possibilitam um divórcio menos traumático e mais humanizado.

O auxílio de uma equipe capacitada e qualificada, que promove uma negociação baseada em interesses, incentiva o exercício da autonomia, reduz antagonismos e auxilia os envolvidos a participarem ativamente na construção de novos comportamentos, por meio de comprometimento e corresponsabilização.

A advocacia colaborativa é, portanto, uma prática sofisticada, uma vez que minimiza os danos emocionais, poupa recursos financeiros, evita a exposição do processo judicial e cuida do sistema familiar como um todo. As partes deixam de ser adversárias para serem vistas como construtoras de uma nova realidade familiar, economizando tempo, como demonstrou o estudo feito pela Academia de Profissionais Colaborativos da Flórida que concluiu que $66 \%$ dos casos colaborativos tem fim em menos de seis meses.

A escolha dessa metodologia possibilita uma maneira viável de solucionar as questões referentes ao divórcio, uma vez que através dela é possível que o conflito seja resolvido de forma mais harmônica, tendo $86 \%$ dos casos apresentados à pesquisa da academia internacional de práticas colaborativas resultado em acordos sobre todos os assuntos. Quando os filhos estão envolvidos no divórcio, mais pertinente se mostra o uso dessa técnica, uma vez que os pais são estimulados a assumirem uma postura colaborativa na criação dos filhos.

Optar por este instrumento é lidar com os conflitos de maneira flexível, criativa e pacífica, assumindo total responsabilidade pela manutenção de vínculos saudáveis e pela tomada de decisões consciente dos impactos que terão.

As práticas colaborativas propõem uma verdadeira mudança de paradigma, difundindo a cultura do diálogo e incentivando os cidadãos a participarem ativamente da construção de soluções para os conflitos que enfrentam.

\section{REFERÊNCIAS}

ALMEIDA, Tania. Mediação de conflitos: para iniciantes, praticantes e docentes. Salvador: JusPodivm, 2016.

ANDOLFI, Maurizio. A crise do casal: uma perspectiva sistêmico-relacional. Porto Alegre: Artmed, 2002.

BRASIL. Constituição da República Federativa do Brasil de 1988. Disponível em: <http://www.planalto.gov.br/ccivil_03/constituicao/constituicao.htm>. Acesso em: 29 abr. 2016.

. Lei $\mathrm{n}^{\mathrm{o}}$ 10.406, de 10 de janeiro de 2002. Institui o Código Civil. Disponível em: <http://www.planalto.gov.br/ccivil_03/LEIS/2002/L10406.htm>. Acesso em: 20 jul. 2015.

CARTER, Betty; McGOLDRICK, Monica. As mudanças no ciclo de vida familiar. Porto Alegre: Artes Médicas, 1995.

CONSELHO NACIONAL DE JUSTIÇA. Curso de mediação de família. Disponível em: <http://www.cnj.jus.br. >. Acesso em: 29 abr. 2016. 
COSTA, Maria Isabel Pereira da. Família: do autoritarismo ao afeto. Como e a quem indenizar a omissão do afeto? Revista Brasileira de Direito de Família, Porto Alegre, v.7, nº 32, out-nov., 2005.

ESCALA de Holmes-Rahe para avaliação do estresse. Disponível em: <http://nenossolar.com.br〉. Acesso em: 29 abr. 2016.

ESTROUGO, Mônica Guazzelli. Direito de família: quando a família vai ao tribunal. In: Aspectos psicológicos na atividade jurídica. Campinas, 2002.

. Litígio de família: quem protege as crianças? In: (Orgs.) AZAMBUJA, Maria Regina Fay de; SILVEIRA, Maritana Viana; BRUNO, Denise Duarte. Infância em família: um compromisso de todos. Porto Alegre: IBDFAM, 2004.

FERRARINI, Letícia; MARCANTÔNIO, Roberta. A mediação familiar para casos de guarda compartilhada: a reafirmação da implementação do instituto no dissenso. In: (Orgs.) ROSA, Conrado Paulino da; THOMÉ, Liane Maria Busnello. Um presente para construir o futuro: diálogos sobre família e sucessões. Porto Alegre: IBDFAM/RS, 2015.

FERRARIS, Anna Oliverio. Filhos de famílias divorciadas e reconstituídas: Identidade e história familiar. In: ANDOLFI, Maurizio. A crise do casal: uma perspectiva sistêmico-relacional. Porto Alegre: Artmed, 2002.

FONKERT, Renata. A mediação e o divórcio colaborativo por equipe interdisciplinar nas situações de divórcio: um enfoque construcionista social e pós-moderno. In: ALMEIDA, Tania. Mediação de conflitos: para iniciantes, praticantes e docentes. Salvador: JusPodivm, 2016.

FÜRST, Olívia. Práticas colaborativas: novos paradigmas do Direito. In: MARODIN, Marilene; MOLINARI, Fernanda. Mediação de conflitos: Paradigmas contemporâneos e fundamentos para a prática. Porto Alegre: Imprensa Livre, 2016.

Práticas Colaborativas no Direito de Família. Disponível em: <https://docs.wixstatic.com/ugd/e910af_2dca64edbf734661b761e5f074dcf740.pdf> Acesso em: 07 ago. 2017

GAMA, Monica Ribeiro de Andrade. Práticas colaborativas: uma nova forma de advocacia que combina parcialidade e colaboração. Disponível em: <http://praticascolaborativas.com.br/home/artigo.php?codigo=51>. Acesso em: 25 mar. 2017.

INNOVARE. Práticas colaborativas no Direito de Família. Disponível em: <http://www.premioinnovare.com.br/praticas/l/praticas-colaborativas-no-direito-de-familia> Aceso em: 07 ago 2017

INSTITUTO BRASILEIRO DE PRÁTICAS COLABORATIVAS. Histórico das práticas colaborativas. Disponível em: http://praticascolaborativas.com.br/home/na-area-defamilia.php\#historico. Acesso em: 07 ago. 2017 
LOBO, Monica; PELAJO, Samantha. Mediação familiar: algumas premissas emocionais e jurídicas. In: ALMEIDA, Tania. Mediação de conflitos: para iniciantes, praticantes e docentes. Salvador: JusPodivm, 2016.

MADALENO, Rolf. Curso de direito de família. 5.ed. Rio de Janeiro: Forense, 2013.

. Guarda compartilhada. In: IBIAS, Delma Silveira. Família e seus desafios: reflexões pessoais e patrimoniais. 2.ed. Porto Alegre: IBDFAM/RS, Letra\&Vida, 2013.

MAZZONI, Henata Mariana de Oliveira; MARTA, Tais Nader. Síndrome de alienação parental. Revista Brasileira de Direito de Família, Porto Alegre, v.21, abr.-maio, 2011.

ORDEM DOS ADVOGADOS DO BRASIL. Resolução nº 02, de 19 de outubro de 2015. Aprova o Código de Ética e Disciplina da Ordem dos Advogados Brasileiros. Disponível em: <http://www.oab.org.br/arquivos/resolucao-n-022015-ced-2030601765.pdf >. Acesso em: 29 abr. 2016.

PESQUISA Estatísticas do Registro Civil 2014. Instituto Brasileiro de Geografia e Estatística (IBGE). Disponível em: <http://www.brasil.gov.br/cidadania-e-justica/2015/11/em-10-anos-taxa-de-divorcioscresce-mais-de-160-no-pais >. Acesso em: 01 abr.2017.

PESQUISA IACP Research Regarding Collaborative Practice (Basic Findings) by Linda Wray on behalf of IACP Research Comitee. Disponível em: < https://www.americanbar.org/content/dam/aba/publications/dispute_resolution_magazine/Wray_rese arch_basic.authcheckdam.pdf>. Acesso em: 10 ago 2017

PESQUISA Research comitee of the Florida Academy of Collaborative Professionals. Disponível em: $<$ http://www.collaborativepracticeflorida.com/groundbreaking-florida-collaborative-divorce-laweffective-july-1-2017/>. Acesso em: 10 ago 2017.

SOUZA, Ionete de Magalhães. Responsabilidade civil e paternidade responsável: análise do abandono afetivo de filho no Brasil e na Argentina. Revista IOB de Direito de Família, São Paulo, v.11, n.58, p.111-126, fev.-mar. 2010.

SOUZA, Monaliza Costa de; GRUBEL, Roselane; PANZENHAGEM, Germana Vogt. O papel do advogado frente à alienação parental. In: (Coord.) SOUZA, Ivone M. Candido Coelho de. Família contemporânea: uma visão interdisciplinar. Porto Alegre: IBDFAM, Letras \& Vida, 2011.

TESLER, Pauline; THOMPSON, Peggy. Collaborative divorce - the revolutionary new way to restructure your family, resolve legal issues and move on with your life. New York: Harper Collins, 2007. 
